\title{
Localized malignant mesothelioma, an unusual and poorly characterized neoplasm of serosal origin: best current evidence from the literature and the International Mesothelioma Panel
}

\author{
Alberto M. Marchevsky ${ }^{1} \cdot$ Andras Khoor $^{2} \cdot$ Ann E. Walts $^{1} \cdot$ Andrew G. Nicholson $^{3} \cdot$ Yu Zhi Zhang ${ }^{3} \cdot$ Victor Roggli $^{4}$ • \\ John Carney ${ }^{4}$ Anja C. Roden ${ }^{5}$ Henry D. Tazelaar ${ }^{6} \cdot$ Brandon T. Larsen $^{6} \cdot$ Nolwenn LeStang $^{7} \cdot$ Lucian R. Chirieac $^{8}$. \\ Sonja Klebe ${ }^{9} \cdot$ Ming-Sound Tsao $^{10}$ - Marc De Perrot ${ }^{10}$ - Andrew Pierre ${ }^{10} \cdot$ David M. Hwang $^{10} \cdot$ Yin P. Hung $\mathbb{C l}^{11}$. \\ Mari Mino-Kenudson ${ }^{11} \cdot$ William Travis $^{12} \cdot$ Jennifer Sauter $^{12} \cdot$ Mary Beth Beasley $^{13} \cdot$ Françoise Galateau-Sallé $^{7}$
}

Received: 5 June 2019 / Revised: 29 July 2019 / Accepted: 30 July 2019 / Published online: 4 September 2019

(c) United States \& Canadian Academy of Pathology 2019

\begin{abstract}
Localized malignant mesotheliomas (LMM) is an uncommon and poorly recognized neoplasm. Its pathologic diagnosis is often surprising in patients with serosal/subserosal based localized tumors that are clinically suspicious for metastatic lesions or primary sarcomas. Once a tumor is diagnosed as "mesothelioma", LMM is often mistaken for diffuse malignant mesothelioma (DMM). Best currently available evidence about LMM was collected from the literature and cases diagnosed by members of the International Mesothelioma Panel (IMP). One hundred and one (101) LMM have been reported in the English literature. Patients had localized tumors with identical histopathologic features to DMM. Patients ranged in age from 6 to 82 years; $75 \%$ were men. Most (82\%) of the tumors were intrathoracic. Others presented as intrahepatic, mesenteric, gastric, pancreatic, umbilical, splenic, and abdominal wall lesions. Tumors varied in size from 0.6 to $15 \mathrm{~cm}$. Most patients underwent surgical resection and/or chemotherapy or radiation therapy. Median survival in a subset of patients was 29 months. Seventy two additional LMM from IMP institutions ranged in age from 28 to 95 years; $58.3 \%$ were men. Sixty tumors $(83.3 \%)$ were intrathoracic, others presented in intraabdominal sites. Tumors varied in size from 1.2 to $19 \mathrm{~cm}$. Median survival for 51 cases was 134 months. Best evidence was used to formulate guidelines for the diagnosis of LMM. It is important to distinguish LMM from DMM as their treatment and prognosis is different. A multidisciplinary approach is needed for the diagnosis of LMM as it shows identical histopathology and immunophenotype to DMM.
\end{abstract}

\section{Introduction}

The serosal membranes include the pleura, peritoneum, pericardium, and tunica vaginalis. They can give rise to benign neoplasms designated as "adenomatoid tumors" and

Alberto M. Marchevsky

Alberto.Marchevsky@cshs.org

1 Departments of Pathology Cedars-Sinai Medical Center, Los Angeles, CA, USA

2 Mayo Clinic Jacksonville, Jacksonville, FL, USA

3 Royal Brompton and Harefield NHS Foundation Trust, London, UK

4 Duke University, Durham, NC, USA

5 Mayo Clinic, Rochester, MN, USA malignant mesotheliomas [1]. The term "mesothelioma" was first coined to describe a tumor reported by Du Bray and Rosson in 1920 [2]. A decade later Klemperer and Rabin further characterized five primary neoplasms of the pleura classifying them as localized or diffuse pleural 
neoplasms [2, 3]. Subsequent studies have shown that mesotheliomas are diffuse or multifocal malignant neoplasms that typically develop in the pleura, less frequently in the peritoneum and other serosal membranes and tend to occur in individuals with a history of asbestos exposure $[1,4-7]$. Patients with diffuse malignant mesothelioma (DMM) have a poor prognosis with median survivals of 6-18 months $[5,8]$.

Whereas many physicians continue to view a diagnosis of "mesothelioma" in terms of this simple framework, more recent studies indicate a more nuanced reality. Although the prognosis of patients with DMM is guarded, multiple factors such as tumor location, histologic subtype, tumor grade, tumor stage, and response to multimodality treatment impact clinical outcome resulting in significantly better survival for some patients [4, 8-11]. It is also now accepted that a substantial number of DMM develop in patients without significant asbestos exposure and that not all "mesotheliomas" are diffuse malignant tumors. Three other neoplasms that partially share the term "mesothelioma" have also been described: well-differentiated papillary mesothelioma (WDPM), localized malignant mesothelioma (LMM), and so-called multicystic mesothelioma [12-26]. WDPM and LMM are associated with considerably better prognoses than DMM [1]. Indeed, WPDM is currently considered as a neoplasm of uncertain malignant potential and multicystic mesothelioma is a benign lesion.

The term "localized mesothelioma" has been poorly defined and used variably in the medical literature to describe a spectrum of mesothelial or mesenchymal tumors that include benign and malignant lesions, and neoplasms of uncertain malignant potential $[16,20,27,28]$. Mesenchymal lesions arising in the pleura, peritoneum or other locations include benign and malignant tumors that do not derive from mesothelial cells and should be distinguished from LMM. They include solitary fibrous tumor, synovial sarcoma, epithelioid hemangioendothelioma, and other mesenchymal tumors [20, 27-32]. Solitary fibrous tumors have been reported in older literature as "localized mesothelioma" or "fibrous mesothelioma" but currently the term LMM is used only to describe tumors of mesothelial origin.

LMM (localized malignant tumors of mesothelial origin) were first described in 1978 by Okike et al., as one of several benign and malignant entities observed in a series of 60 localized pleural lesions. In 1992 Henderson et al. briefly described two cases of LMM in their book on malignant mesothelioma; one of the patients had documented asbestos exposure [33]. LMM was further characterized as a distinct clinicopathologic entity in 1994 by Crotty et al. in their detailed description of the clinicopathologic features of six patients with this rare tumor [34-36]. The patients ranged from 42 to 76 years of age and only three had a history of asbestos exposure [34]. Three of the neoplasms were epithelioid and three were biphasic. Three of the patients developed local recurrences and died from their disease, while the other three survived without recurrence for 8 to 96 months after diagnosis. This report was followed by a series of 23 LMM described by Allen et al. in 2005, multiple smaller series and case reports [16-23, 27, 28, 32, 34-74]. The 21 pleural and two peritoneal tumors reported by Allen et al. remains the largest published series to date [37]. These cases were diagnosed using the following criteria: "radiologic, surgical, or pathologic evidence of a localized serosal/subserosal (but not organ centered) tumor mass without evidence of diffuse serosal spread and a microscopic pattern identical to that found in ordinary DMM" [37]. Amongst their 23 tumors, $16(69.5 \%)$ showed epithelioid features, $6(26 \%)$ had biphasic morphology, and 1 (4.5\%) was sarcomatoid. Following local resection $\sim 50 \%$ of the patients were alive from 18 months to 11 years after diagnosis, suggesting a substantially better prognosis than for DMM patients. Asbestos exposure history was only available for five patients. Four of the patients (80\%) had a history of asbestos exposure but, without information on the other 18 cases, the authors were unable to determine the role of asbestos in causation of this neoplasm. Others, albeit using variable criteria to diagnose a malignant mesothelioma as "localized", have generally supported the concept that LMM can often be completely excised/resected resulting in a better outcome than for individuals with DMM [16-23, 27, 28, 32, 34-74]. Nevertheless, because LMM are rare and share identical histopathologic features with DMM in biopsies, they are often simply diagnosed as "mesotheliomas" by pathologists and reflexively interpreted as DMM by oncologists. The current study describes the clinicopathologic features of 72 additional cases diagnosed as LMM by members of the International Mesothelioma Panel (IMP) and proposes opinion-based guidelines for diagnosis, based on the consensus interpretation of available best current evidence.

\section{Materials and methods}

IMP is a group of pathologists from the United States, Europe, Asia, and Australia that aims to advance the understanding of serosal neoplasms and is currently chaired by Dr Françoise Galateau-Sallé, director of MESOPATH (Lyon, France). The collaboration has previously developed evidence-based guidelines for the diagnosis of biphasic and sarcomatoid malignant mesotheliomas and contributed other collaborative studies [75, 76]. A comprehensive review of the English literature was performed using the PubMed search engine of the Library of Medicine and "localized malignant mesothelioma", "pleura", "peritoneum", "pericardium", "abdomen", "liver", and "extrathoracic" as search terms. Cases reported as localized mesothelioma that showed pathologic features of a solitary fibrous tumor, a 
tumor that lacked well defined borders or infiltrated into adjacent tissues, and diffuse or multifocal mesotheliomas were excluded. Mesotheliomas of the tunica vaginalis were arbitrarily excluded from the literature review because they often lack a well-defined border and are usually described as a distinct clinicopathologic entity rather than as LMM or DMM. Members of IMP were invited to contribute clinicopathologic information for cases diagnosed as LMM at their institutions and provide all available data for these patients and their tumors including age and gender, occupational history, pathologic features, selected imaging features, treatment, and outcome. The available data were queried using the approach previously adapted from evidence-based medicine by Marchevsky and Wick [77-79]. The specific questions listed in Table 1 were formulated and evidence summaries from all cases contributed by IMP members were prepared by one of the authors (AMM). Survival data for LMM patients who survived at least 1 month after diagnosis were analyzed with Kaplan-Meier method using Medcalc 19.0.4 software (Medcalc, Ostend, Belgium). Survival curves were compared using the Log rank test. The results were discussed among all coauthors at a meeting of IMP held in National Harbor, MD in March 2019 and in subsequent electronic communications and used to propose evidence-based guidelines for the diagnosis of LMM.

\section{Results}

The literature review identified 101 cases of LMM described in 51 publications from 1978 until 2019; 45 of the cases were reported in single case reports $[16,21,34-39,41-$ $44,46,48,50-53,55-61,63-66,68-74,80-91]$. Criteria for the diagnosis of LMM were suggested by Allen et al., as described above [37]. Other studies did not explicitly describe their diagnostic criteria. None of the studies stated whether size cutoffs or depth of invasion should be used to exclude the classification of a tumor as LMM and some studies accepted this diagnosis in the presence of multiple well-defined nodules and/or localized pleural thickening adjacent to a dominant mass. There is no explicit information in the literature to determine whether the presence of a serosal effusion or the identification of cytologically atypical cells in an effusion was or should be used to exclude a diagnosis of LMM. Similarly, there are no published studies recommending that negative thoracoscopic biopsies taken from grossly unremarkable serosa away from the localized mass or that a minimum follow-up period be required to diagnose a localized tumor of serosal origin as LMM.

Table 2 summarizes the findings from each of the published case series reporting two or more cases diagnosed as LMM. None provides data to estimate the incidence of
Table 1 Questions used to query the literature and our own experience regarding the clinically relevant features of localized malignant mesothelioma

-What is the incidence of localized malignant mesothelioma?

-Are the age and gender of patients with localized malignant mesothelioma significantly different than for patients with diffuse malignant mesothelioma?

-Do patients with localized malignant mesothelioma have a significant history of asbestos exposure that could have caused a diffuse malignant mesothelioma?

-Is the site distribution of localized malignant mesothelioma like that in diffuse malignant mesothelioma?

-Were the criteria to define a malignant mesothelioma as "localized" explicitly described in the cases reported in literature?

-Is there a minimum or maximum size cut-off that would exclude a diagnosis of localized malignant mesothelioma?

-Does the presence of a small number of lesions (e.g., 2 or 3 apparently well circumscribed nodules or a predominant mass accompanied by other smaller nodules) exclude the diagnosis of localized malignant mesothelioma?

-Does the presence of pleural effusion or other serosal effusion exclude the diagnosis of localized malignant mesothelioma?

-Does the presence of atypical cells in serosal effusion associated with a localized mass exclude the diagnosis of localized malignant mesothelioma?

-Are imaging studies sufficient for a diagnosis of mesothelioma as localized malignant mesothelioma or is thoracoscopy required to exclude the presence of additional small lesions in a patient with a localized mass?

-Are thoracoscopic biopsies of grossly unremarkable serosal surfaces away from the area of a localized mass necessary to diagnose a mesothelioma as localized malignant mesothelioma?

-Does the diagnosis of localized malignant mesothelioma require a minimum follow-up period to exclude the possibility of diffuse malignant mesothelioma?

-How were patients with localized malignant mesothelioma treated?

-What is the prognosis of patients with localized malignant mesothelioma?

-Is the prognosis of localized malignant mesothelioma patients similar to those with pT1 diffuse malignant mesothelioma?

-Is localized malignant mesothelioma a different tumor than diffuse mesothelioma or is it part of a continuum of malignant neoplasms of mesothelial origin?

LMM at the respective institutions. The $101 \mathrm{LMM}$ included 76 men $(75 \%)$ and 25 women $(25 \%)$, yielding a male/ female ratio of 3.04. Patients ranged in age from 6 to 82 years with a mean age of $58.9 \pm 13.9$ years. Information regarding asbestos exposure was reported for 78 patients, including some reported as single case reports that are not shown in Table 3; 29 patients $(37.2 \%)$ had asbestos exposure, but the type and length of exposure is not described. Interestingly, the patient reported by Sasaki et al. had asbestosis, a condition usually associated with exposure to high doses of asbestos [68]. In imaging studies 82 of the cases $(82 \%)$ were described as localized thoracic tumors 


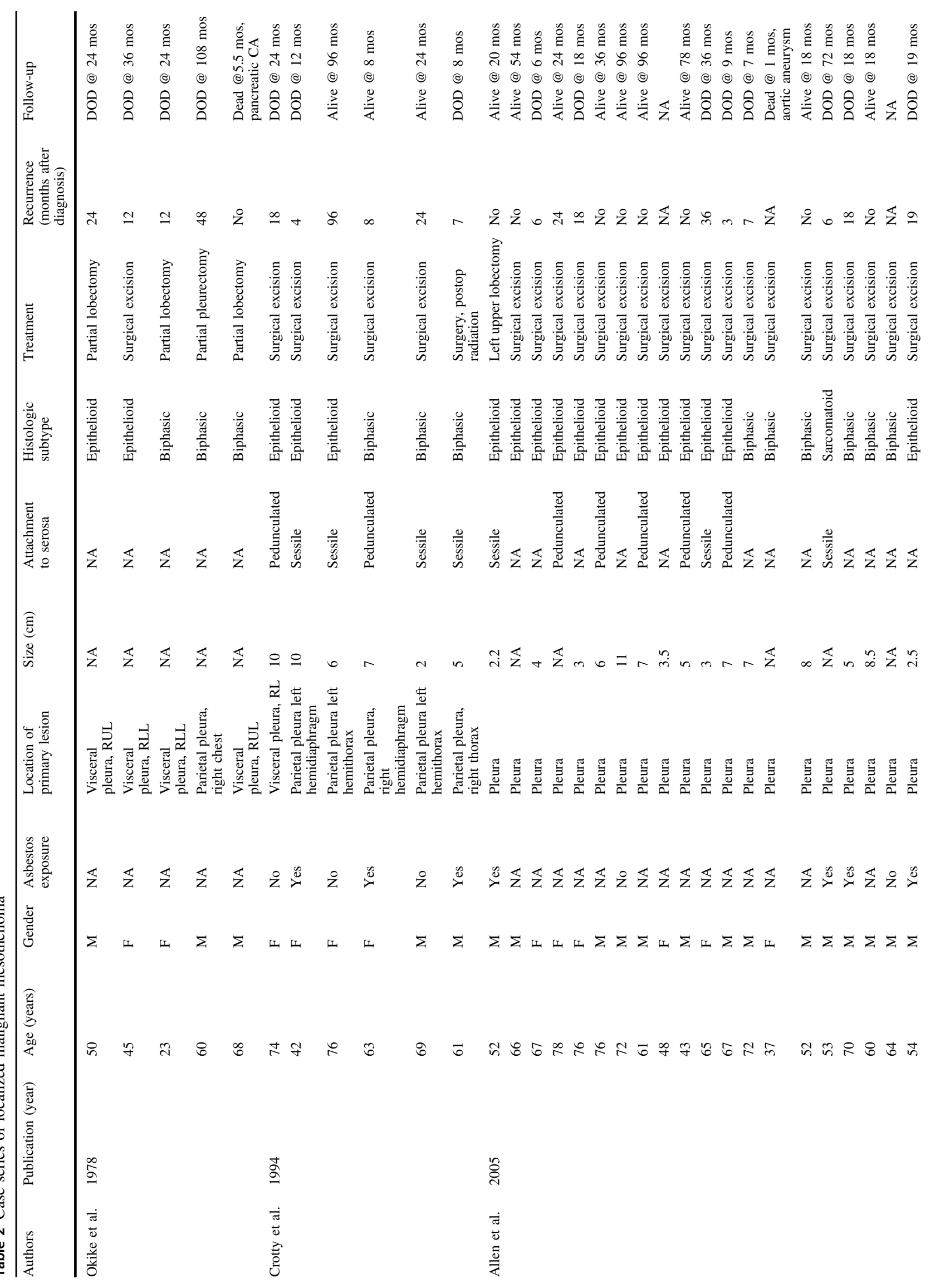




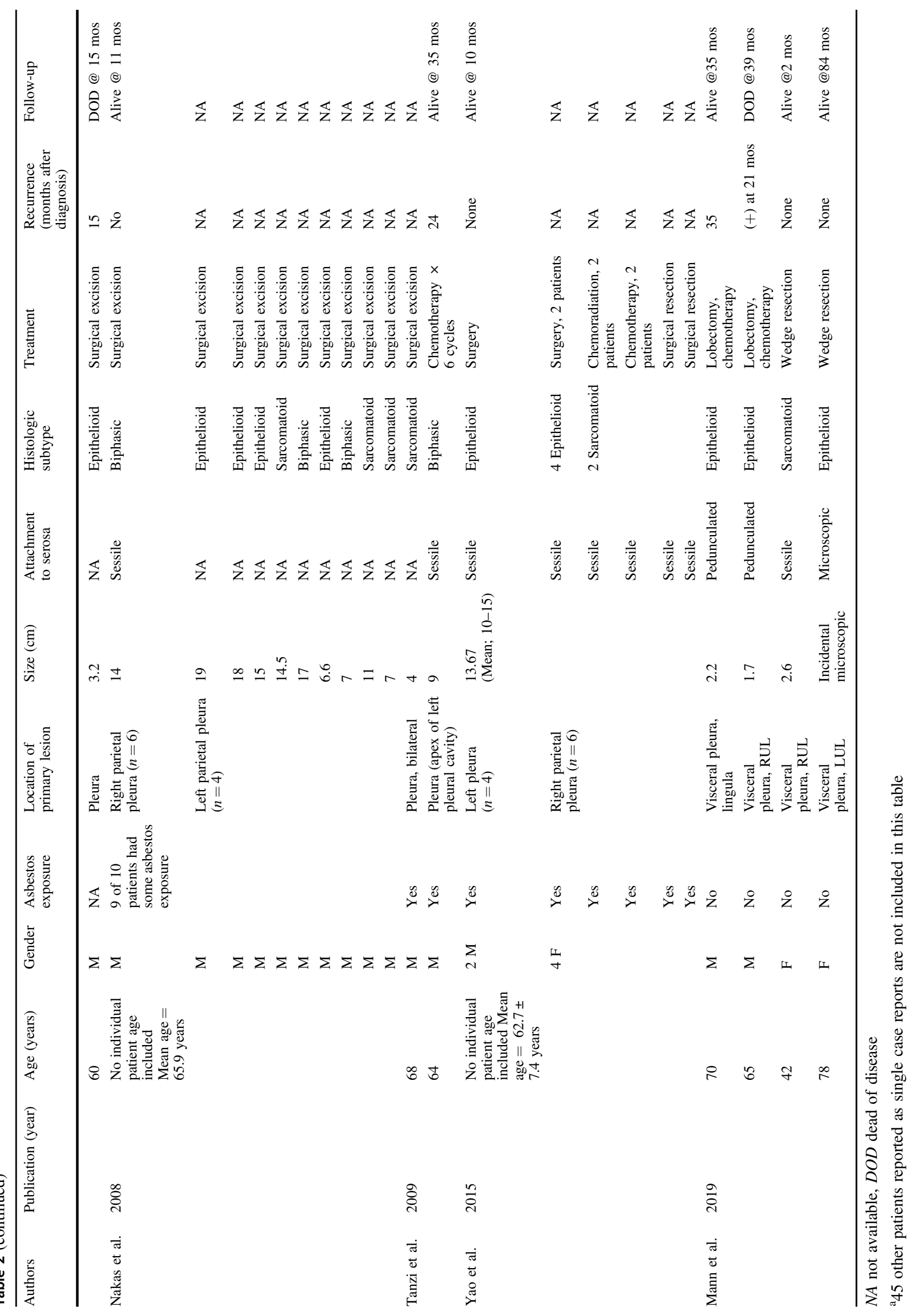




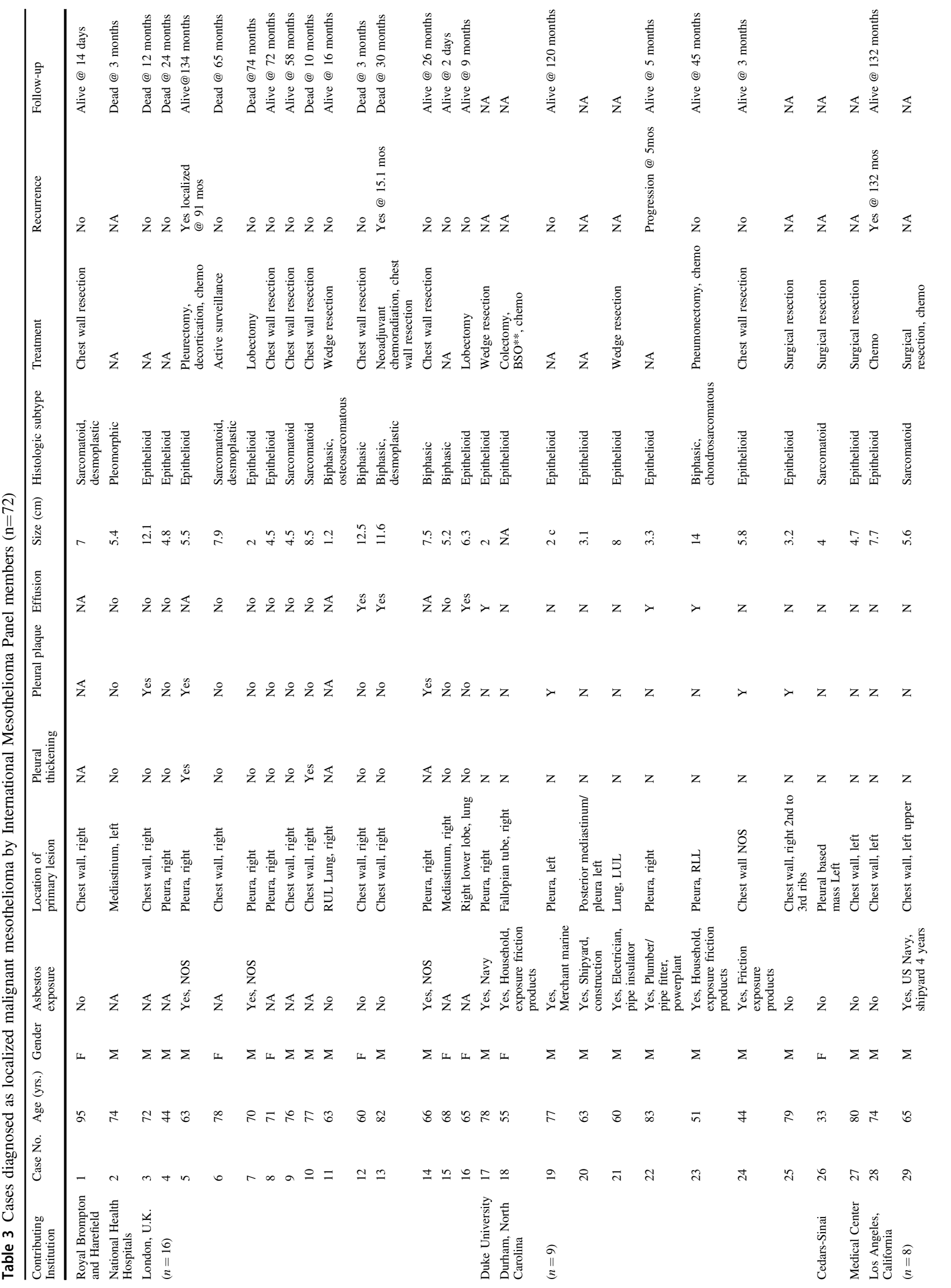




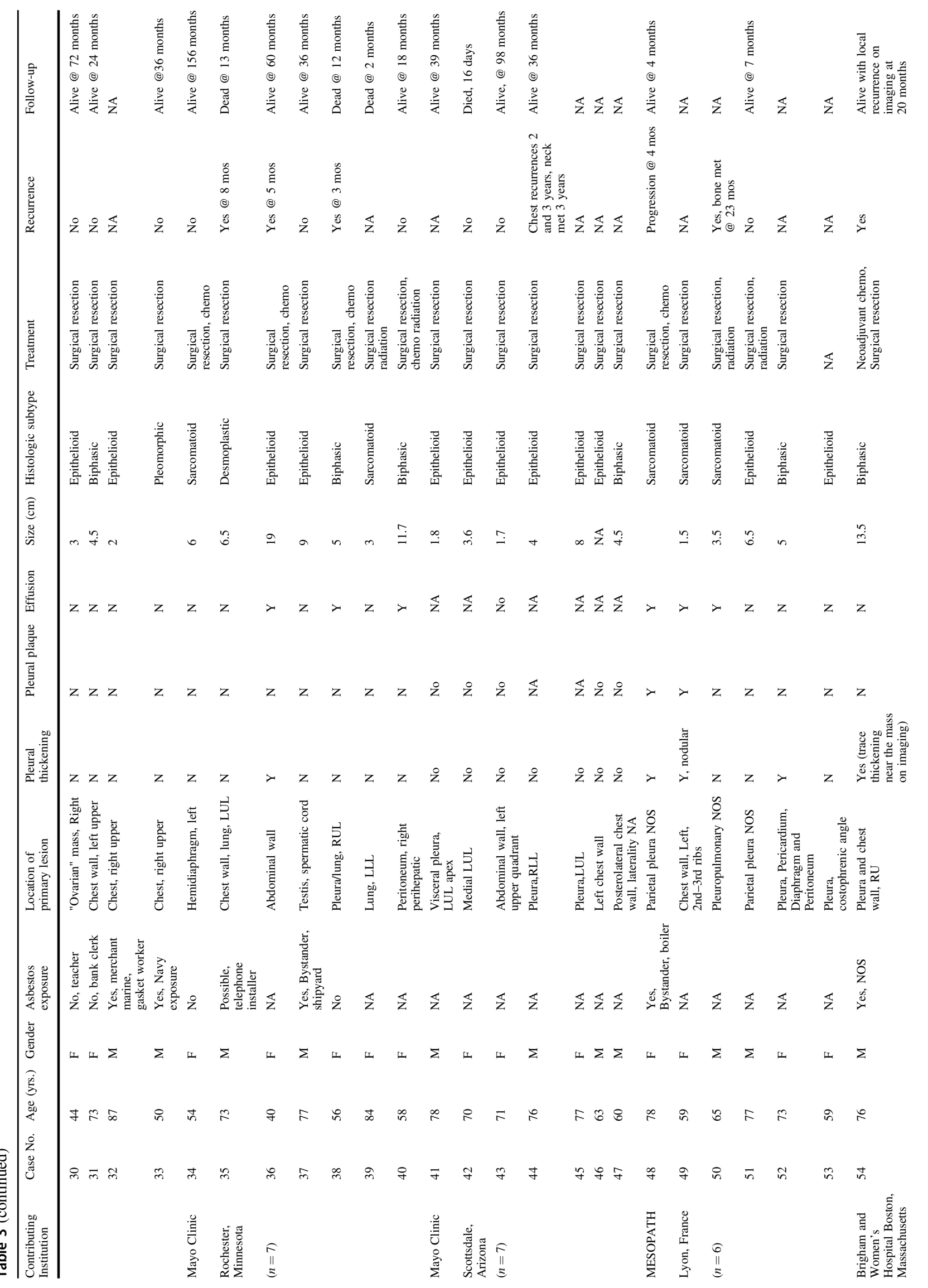




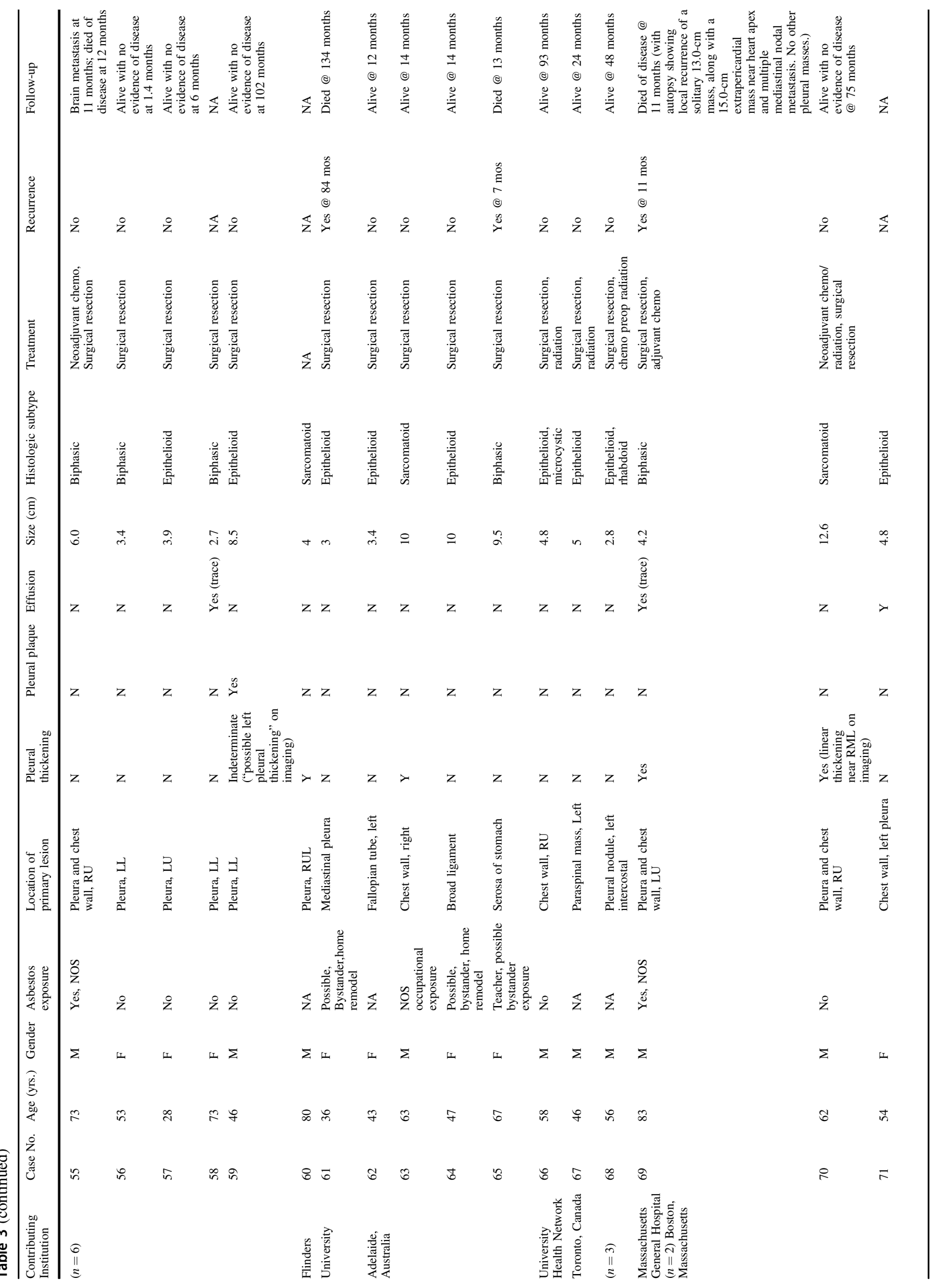




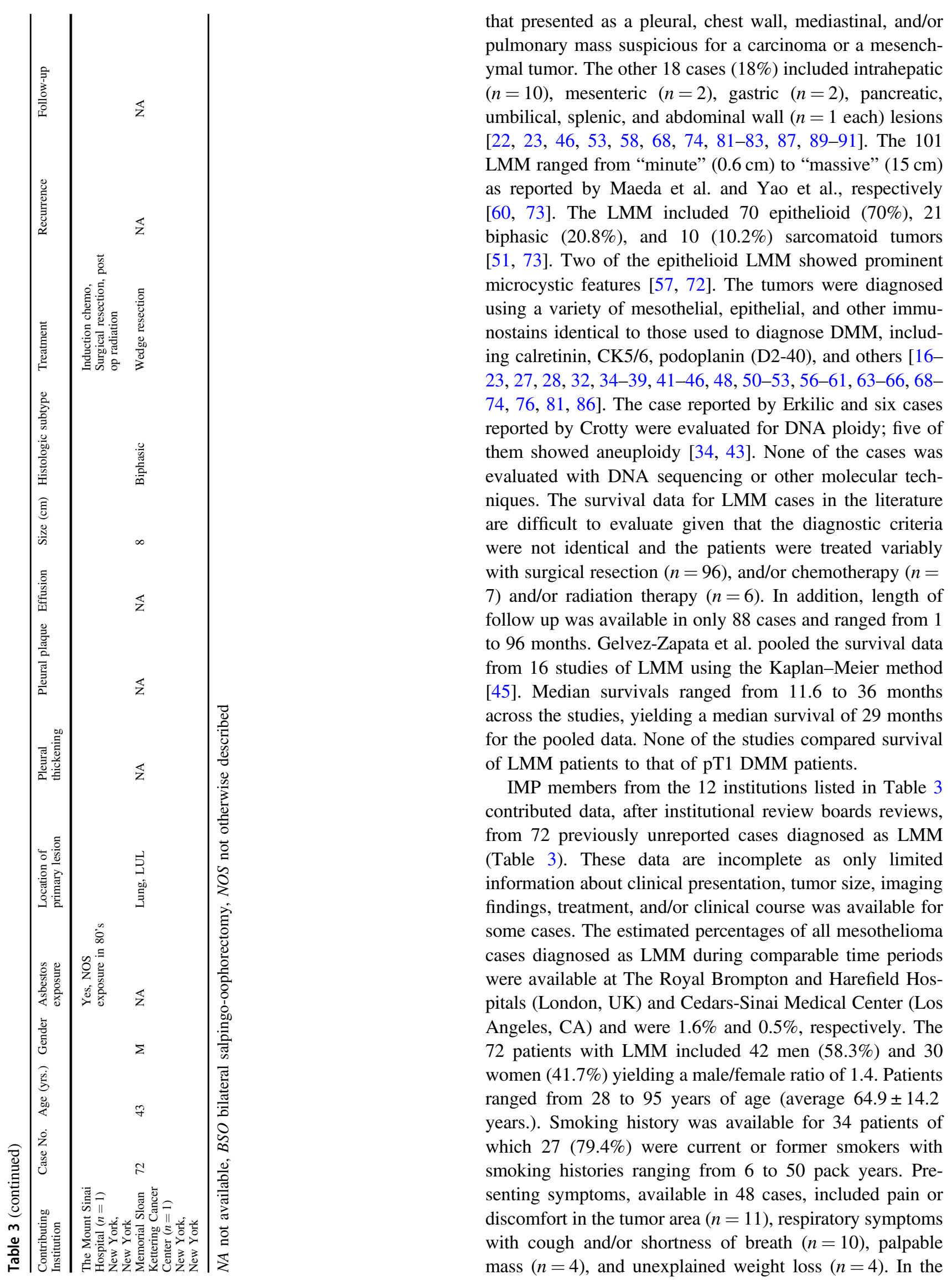


other 19 patients an asymptomatic mass was found on imaging or during abdominal surgery performed for another condition. To our knowledge, presumptive clinical diagnoses ranged from carcinoma to mesenchymal lesions dependent on the tumor location; mesothelioma was not suspected clinically in any of the patients. Sixty three LMM were intrathoracic $(87.5 \%)$ and presented as a localized pleural, chest wall, pulmonary, or mediastinal mass. Laterality was described in 57 cases; tumors were slightly more frequent in the right $(n=30,54.5 \%)$ than the left $(n=27$, $44.5 \%)$ sides. Nine LMM $(12.5 \%)$ were intrabdominal tumors arising from the fallopian tube $(n=2)$, abdominal wall $(n=2)$, ovary $(n=1)$, perihepatic $(n=1)$, gastric serosa $(n=1)$, tunica albuginea $(n=1)$, and broad ligament $(n=1)$.

Information about asbestos exposure was available in the clinical and/or occupational history of 38 patients. In 21 $(55.2 \%)$ of these patients, notations in the clinical or occupational history described asbestos exposures ranging from three patients who reported household exposure from a relative who was a mechanic or had performed some home remodeling to more definitive occupational exposures in three patients who worked in shipyards and/or the U.S. Navy. The presence of pleural plaques indicative of probable above background asbestos exposures was reported in seven patients. Lung tissue was not sampled in all 72 patients. The presence of asbestos bodies in lung tissue was reported in only two patients; one showed only rare asbestos bodies, the number of asbestos bodies was not quantified in the other case. Tissue burden analysis was performed in one case; the lung tissue showed tremolite fibers in concentration consistent with background levels.

Imaging findings in addition to a localized mass (Fig. 1A) were reported in 26 patients and included pleural effusion ( $n=14)$, pleural thickening (Fig. 1B) $(n=8)$, and/ or pleural plaque $(n=7)$. Cytologic evaluation showed malignant cells in a pericardial fluid and cells suspicious for malignancy in a pleural fluid. Biopsies of serosal membranes taken away from the localized tumor were available in seven cases; five pleural biopsies were negative for tumor; one pericardial biopsy was positive for tumor and a peritoneal biopsy showed endometriosis.

Grossly, the LMM were well circumscribed, nonencapsulated or partially encapsulated lesions (Fig. 2) ranging from 1.2 to $19 \mathrm{~cm}$ (average $6 \pm 3.7 \mathrm{~cm}$ ). The 72 tumors included epithelioid $(n=39)$ (Fig. 3A), biphasic $(n=18)$ (Fig. 3B), and sarcomatoid ( $n=15)$ (Fig. 3C) LMM. The 39 epithelioid LMMs included tumors with pleomorphic $(n=2)$, microcystic $(n=1)$, and rhabdoid $(n=1)$ features. The 15 sarcomatoid LMMs included desmoplastic $(n=3)$ and lymphohistocytoid $(n=1)$ lesions. The biphasic LMMs included one lesion with an osteosarcomatous component, one with chondrosarcomatous differentiation, and one with

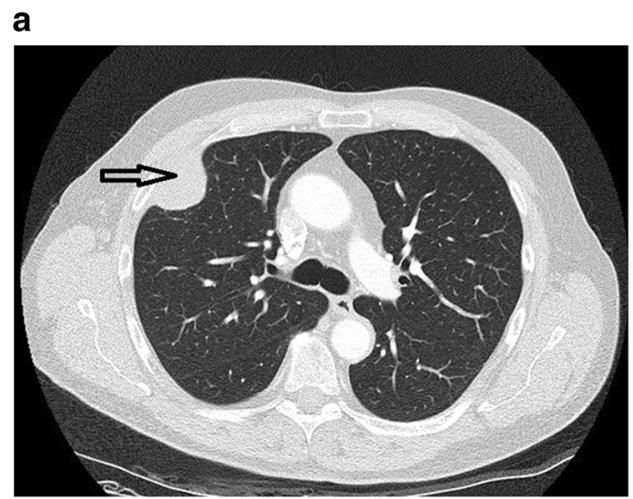

b

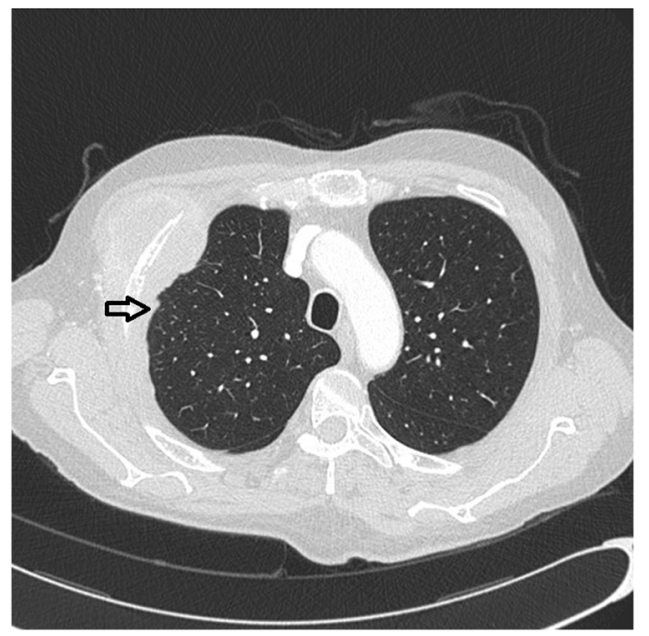

Fig. 1 a Chest CT scan showing a localized pleural based mass. Notice the absence of other significant intrathoracic findings. b Chest CT showing a localized pleural based mass and mild, slightly nodular pleural thickening adjacent to the lesion (arrow). Areas such as this need to be biopsied to exclude the possibility of diffuse malignant mesothelioma prior to diagnosing a tumor as localized malignant mesothelioma

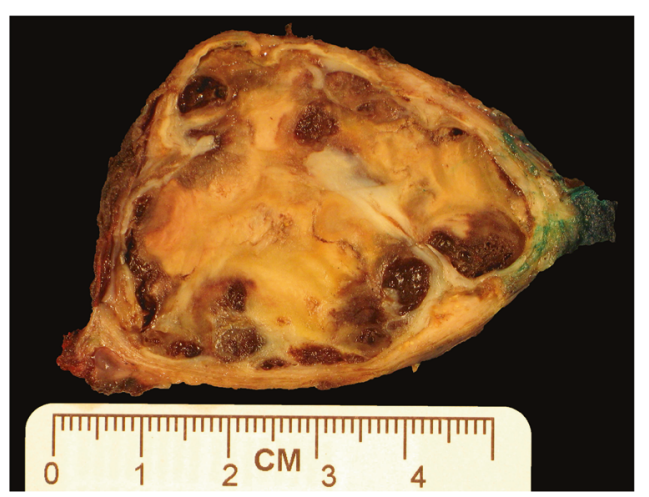

Fig. 2 Gross photo of pleural localized malignant mesothelioma

features of desmoplastic mesothelioma. Histologic grade was available in 26 epithelioid LMM: grades I $(n=7)$, II $(n=8)$, and III $(n=11)$. The LMM were immunostained 
Fig. 3 a Photomicrograph of epithelioid localized malignant mesothelioma (H\&E, 200x).

The lesion shows tubulopapillary growth features and is composed of mildly pleomorphic epithelioid cells that infiltrate the parietal pleura. b Photomicrograph of biphasic malignant mesothelioma (H\&E, 200x). The tumor is composed of epithelioid cells forming tubules and solid sheets admixed with malignant spindle cells. c Photomicrograph of sarcomatoid localized malignant mesothelioma (H\&E, 400x).

The lesion is composed of solid sheets of pleomorphic tumor cells. The diagnosis of localized malignant mesothelioma needs to be suspected during the evaluation of serosal/subserosal tumors so that appropriate immunostains are performed and the tumor is not mistaken for a sarcoma
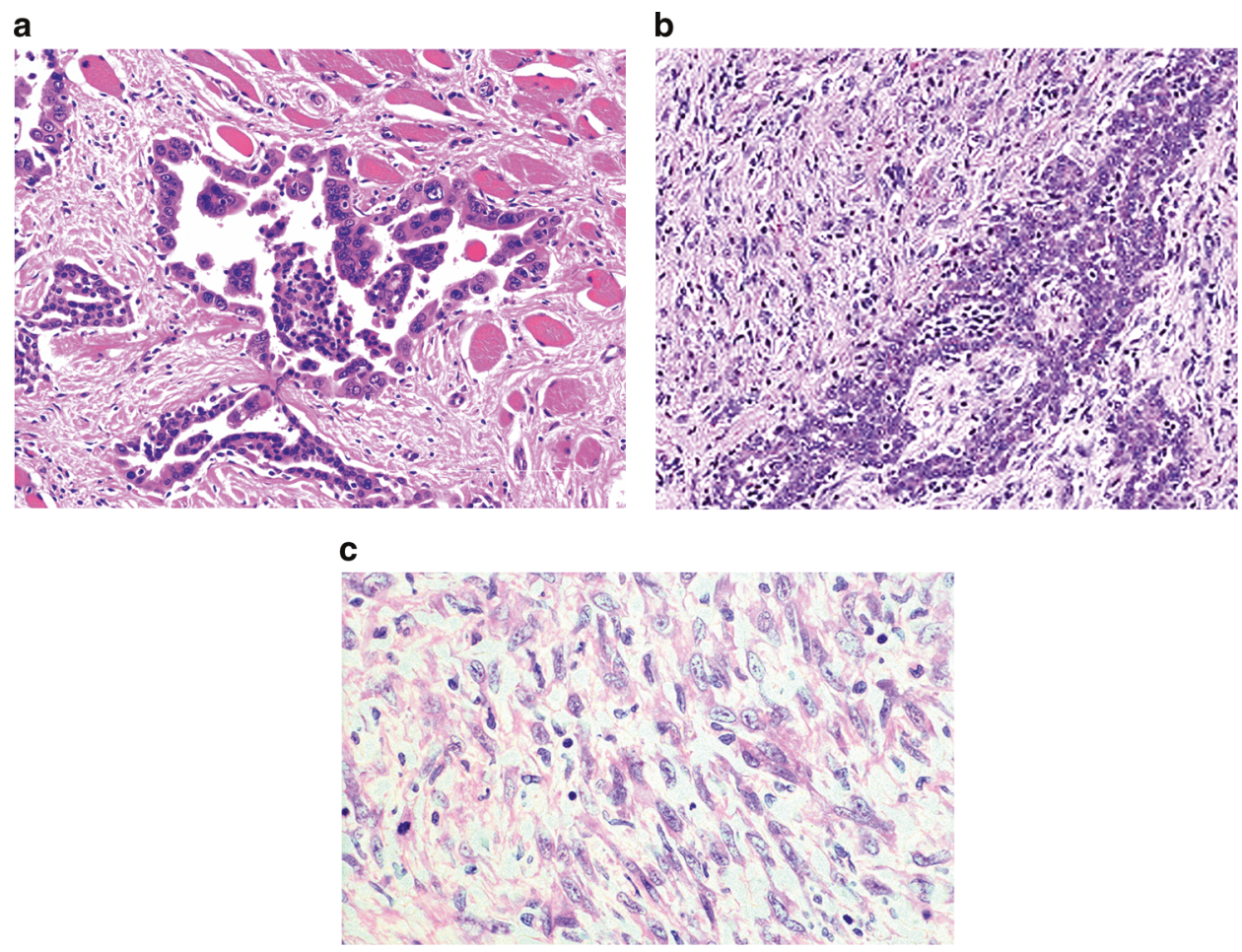

with up to 19 antibodies/case (Fig. 4A and B), reflecting the fact that many of the cases represented referrals and the diagnosis of mesothelioma was probably not initially favored and possibly not even considered in the differential diagnosis at the time of initial pathologic examination of a localized tumor. The lesions showed similar immunoreactivity to cases of DMM. One of three cases studied for BAP-1 showed loss of immunoreactivity. None of the three cases studied with CDKN2A (p16) FISH showed homozygous loss. One case was studied at MESOPATH with molecular methods; it showed fusion transcripts USP22CD- RT4 and a P.Y646/c mutation in exon 15 of the BAPI gene. The 6 cases contributed by the Brigham and Women's Hospital were evaluated with karyotypic analysis and targeted next-generation sequencing by Hung et al (In Press Mod. Pathol 2019).

Clinical information about treatment was available in 63 (87.5\%) of the 72 cases. Fifty-six of the 63 patients (88.9\%) were treated with local resection NOS, chest wall resection, pleurectomy/decortication, lobectomy, colectomy, bilateral salpingo-oophorectomy, pneumonectomy, extrapleural pneumonectomy, and/or lung wedge resection (see Table 3). Resection margin status was available for 42 of the resected tumors and it was free of tumor in $37(88 \%)$ cases and positive for tumor in $5(12 \%)$ cases. Eleven of the 63 patients received postoperative chemotherapy $(17.5 \%)$, six $(9.5 \%)$ were treated with neoadjuvant chemotherapy and/or radiation therapy, and one was treated only with chemotherapy. Six patients $(9.5 \%)$ were treated with postoperative radiation therapy. Outcome information was available for 53 (73.6\%) of the 72 LMM patients but two patients died within 1 month of diagnosis, so survival analysis was performed on 51 (70.8\%) cases. Recurrences were reported in 14 of the 51 (27.4\%) patients. Available information about the clinical and imaging details of these recurrences is incomplete to determine the type of recurrence, with some patients having developed single or multiple nodules (Fig. 5) and others diagnosed with disease progression. All the 14 cases that developed recurrences had been treated with surgical resection. Margin status was available in 11 of those cases and was reported as involved by tumor in only 1 of the 11 cases. All but 2 of the 14 recurrences were intrathoracic. One patient developed bone metastasis and another developed brain metastasis. Figure 6 shows the survival curve for the 51 LMM patients. Median survival was 134 months $(95 \% \mathrm{CI}=$ 65-134 months). Median survivals by LMM subtype were 134 months (95\% CI $=74-134$ months), 65 months (95\% $\mathrm{CI}=2-65$ months $)$ and 30 months $(95 \% \quad \mathrm{CI}=$ 65-134 months) for epithelioid, sarcomatoid, and biphasic lesions, respectively. Survival curves were significantly different $($ Chi-squared $=6.45, p=0.039, \mathrm{DF}=2)$.

\section{Discussion}

LMM is a rare neoplasm that exhibits histopathological and immunophenotypical features identical to DMM. It has been identified in only $0.5-1.6 \%$ of cases diagnosed as malignant 

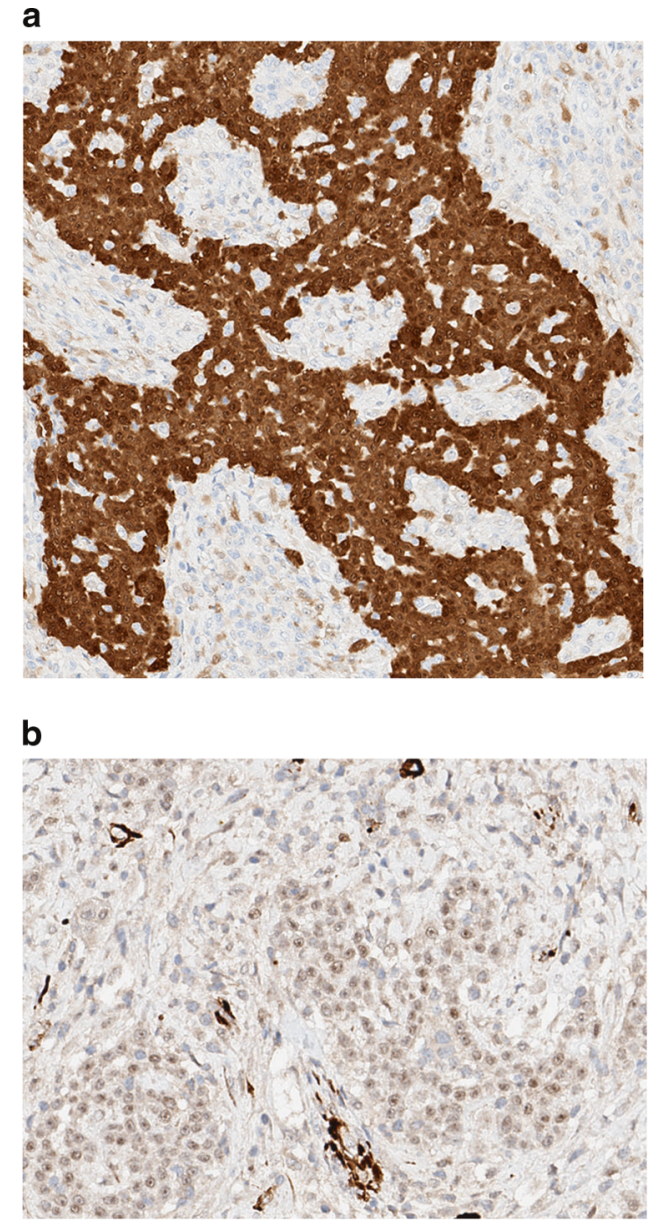

Fig. 4 a Epithelioid localized malignant mesothelioma. The tumor cells exhibit strong nuclear and cytoplasmic immunoreactivity for calretinin (PAP, 100x). b Epithelioid localized malignant mesothelioma. The tumor cells exhibit nuclear immunoreactivity for WT-1 (PAP, 100×)

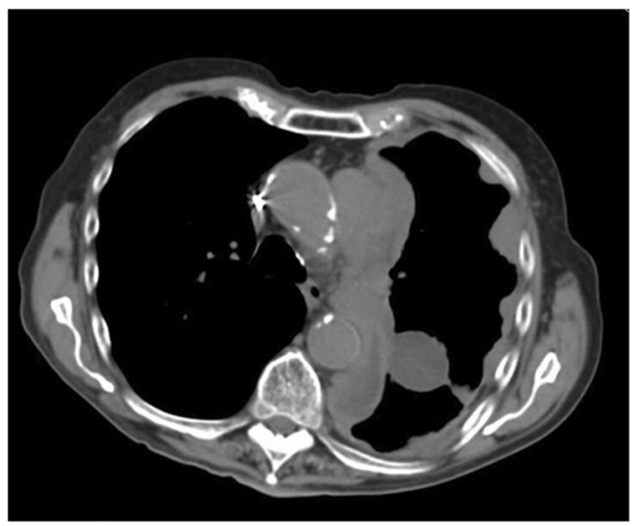

Fig. 5 Recurrent epithelioid localized malignant mesothelioma of the left chest. Chest CT scan shows that the tumor recurred 11 years after complete resection as a diffuse malignant mesothelioma exhibiting multiple tumor nodules and pleural thickening

mesothelioma in two of the institutions participating in the IMP. Review of the 101 cases from the literature shows that LMM has been reported mostly as case reports and small

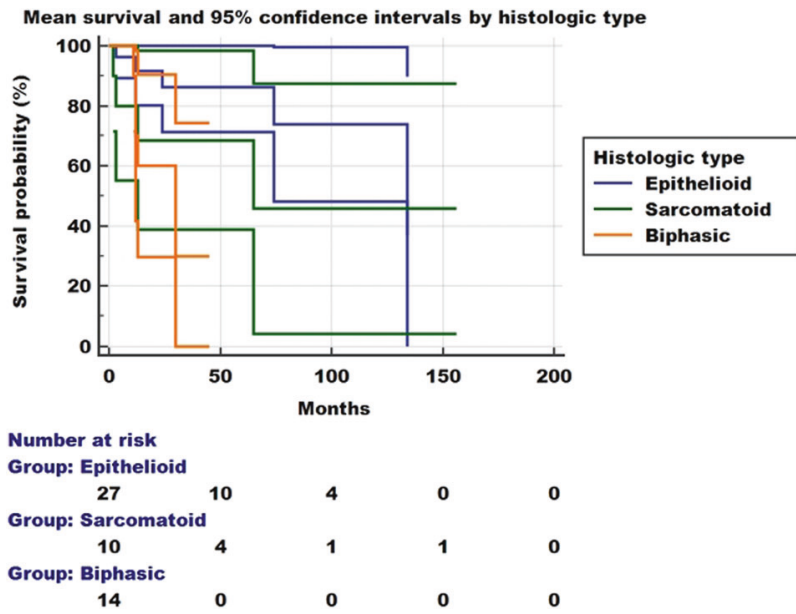

Fig. 6 Survival curve of 51 patients with localized malignant mesothelioma. The median survival was 134 months, considerably better than for patients with diffuse malignant mesothelioma. Patients with epithelioid lesions had a significantly better survival than those with sarcomatoid or biphasic tumors

series using various interpretations of the criteria suggested by Allen et al. to diagnose a malignant mesothelioma as "localized" [37]. For example, some of the studies shown in Table 1 included a well-circumscribed malignant mesothelioma associated with a few small nodules adjacent to but separate from the main tumor, with limited pleural thickening and/or with pleural effusion, while other studies only reported single, localized tumors without these additional findings. Indeed, when the clinicopathologic features of cases reported as LMM in the literature and diagnosed as LMM by IMP members were reviewed and discussed in detail, it became apparent that there have been differences in diagnostic opinions. For example, among cases in the literature that have shown serosal effusion, it is not always made clear whether cytology was negative. LMM-associated effusions in IMP cases ranged from trace amounts to large pleural effusion or ascites and showed a negative cytology. Panel members opined that the presence of pleural or other serosal effusion does not preclude a diagnosis of LMM provided that cytology is negative for malignant cells. IMP members also discussed whether biopsies of serosal membranes away from the localized mass should be required for a diagnosis of LMM and acknowledged that this may not be practical, as a diagnosis of LMM is seldomly made or even considered preoperatively or intraoperatively. However, as thoracic surgeons become more familiar with LMM it may be useful to obtain several pleural biopsies during thoracoscopy or resection of these lesions, in order to exclude microscopic DMM in cases where the differential diagnosis at frozen section includes LMM. Neither the literature nor IMP members found evidence that would require the passage of a stated minimum amount of time after initial detection of a localized mass to classify a malignant mesothelioma as LMM; the diagnosis of LMM is based on 
the presence of a localized mass at the time of diagnosis and that the appearance of subsequent additional nodules in LMM patients is diagnosed as local recurrence. Table 4 summarizes the opinion-based diagnostic criteria for LMM that are derived from the consensus interpretation of current best available evidence. Applying these criteria retrospectively would result in the reclassification of certain LMM cases as DMM. For example, cases 10, 48, and 52 (Table 3) showed nodular thickening on chest CT scan. Each of these patients had a distinct tumor involving the pleura but the presence of additional smaller nodules was not excluded by additional biopsies. Cases 54, 59, and 68 present more difficult diagnostic dilemmas, as they showed trace pleural thickening near the mass. Such linear thickening without nodularity is more likely secondary to pleural fibrosis and less concerning than nodular pleural thickening for a DMM. Only 1 of the 72 cases diagnosed as LMM by IMP members developed as a testicular mass (case 37) probably arising from the tunica albuginea. Mesotheliomas of the tunica vaginalis have been described as a distinct entity and grouped with peritoneal DMM, although it is possible that some lesions could develop as LMM arising at other sites [92-96].

LMM occurs in patients of all ages and the diagnosis generally came as a surprise to surgeons and oncologists who had expected a diagnosis of carcinoma, sarcoma, or other mesenchymal tumor in patients presenting with a localized mass. The diagnosis of sarcomatoid LMM can be

Table 4 Proposed guidelines for the diagnosis of Localized Malignant Mesothelioma $^{\mathrm{a}}$

Imaging studies: well circumscribed serosal/subserosal mass of any size

Absence of additional nodules or other evidence of diffuse serosal spread in the pleura, pericardium or peritoneum

Presence of serosal effusion (e.g., pleural effusion, ascites, pericardial effusion) does not exclude the diagnosis if cytology is negative for malignant cells (see below)

Presence of pleural, pericardial or peritoneal thickening adjacent to the tumor raises questions about the diagnosis; malignancy needs to be excluded by biopsy of any serosal abnormality other than the localized mass

Thoracoscopy or laparoscopy: absence of additional tumor nodules; Biopsy all pleural abnormalities

Biopsies of grossly normal serosa away from the tumor are not required for diagnosis

Cytology: absence of malignant cells in effusion, preferably confirmed by loss of BAP-1

immunoreactivity in the malignant cells (benign mesothelial cells retain $\mathrm{BAP}-1$

immunoreactivity) and/or $C D K N 2 A$ p16 loss of heterozygosity in atypical mesothelial cells

Histopathology: presence of histopathologic features and immunophenotype that are identical to those of diffuse malignant mesothelioma

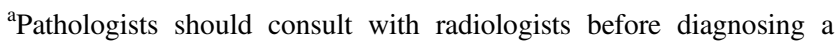
tumor as localized malignant mesothelioma particularly difficult to distinguish from other spindle cell neoplasms, as sarcomatoid mesotheliomas often stain negatively with various mesothelial markers [76]. One of the intriguing findings in our case cohort was the relatively large number of LMM diagnosed at one institution. This was attributed to the fact that this institution is a referral center for chest sarcomas; indeed, one of their cases was initially diagnosed as a sarcoma NOS and later reclassified as a sarcomatoid LMM after evolving into a DMM a few months after initial treatment. The distribution of patients by gender is only slightly different between LMM and DMM, as $70-75 \%$ of LMM and $80 \%$ of DMM occur in males $[11,97]$. There is insufficient evidence to determine if exposure to asbestos increases the risk for development of LMM because information about exposure to this carcinogen is scant and relevant epidemiologic studies are lacking. A history of occupational and/or household asbestos exposure has been reported in about $30 \%$ of cases and was described in $55.2 \%$ of IMP cases, but information about length and dose of exposure and/or fiber type is lacking in most instances. The relative proportions of pleural and peritoneal mesotheliomas appear to be similar for patients with LMM and DMM [11, 97]. In 82-90\% of patients LMM occurs as an intrathoracic tumor, where it can appear as a pleural based mass, chest mass, mediastinal tumor, esophageal tumor, intrapulmonary lesion or, very rarely, as a localized pericardial neoplasm [16-23, 27, 28, 32, 34-74]. Extrathoracic LMM have developed as intrahepatic, splenic, gastric, mesenteric, testicular, or fallopian tube lesions.

Most LMM patients have been treated with various surgical techniques but there is limited information regarding margin status in the published cases. This information was available in 42 of the IMP patients; R0 resections were reported in $88 \%$ of them. Interestingly, 10 of the 11 recurrent IMP tumors with available information about margin status had negative margins at the time of initial resection. Use of chemotherapy and radiation therapy was also variable in the literature and our own cases. Only level 4 or 5 evidence is available regarding the clinical course of patients diagnosed with LMM in the literature, and follow-up time periods varied widely among the cases contributed by IMP members; hence it is not possible to provide accurate prognostic estimates for these patients. Using Kaplan-Meier statistics Gelvez-Zapata et al. estimated a 29 months median survival for $48 \mathrm{LMM}$ patients. Median survival in 51 the IMP patients is 134 months, with significantly shorter median survivals in those with sarcomatoid and biphasic lesions than for epithelioid LMM. However, the statistical analysis need to be interpreted with caution, as the data were collected from patients treated variably at multiple institutions and followed for variable time intervals.

Our study confirms that patients with LMM have considerably more favorable survival than DMM patients. 
There are no studies that directly compare the survival of LMM patients with early stage DMM patients and WDPM individuals. A recent study by the International Association Study of Lung Cancer, reports median survivals of 23-40 months among stage I DMM patients who underwent resection of intrathoracic tumor, depending upon whether the resection was performed with curative versus palliative intent [11, 97]. Malpica et al. reported in a study of 26 WDPM that 22 patients with available follow up had survivals ranging from 4 to 192 months (47.5 \pm 32 months) [98]. Additional prospective studies of LMM patients using standardized diagnostic criteria and treatment protocols and longer follow up are needed to estimate the prognosis of these patients with greater accuracy.

In summary, our study outlines the clinicopathologic features of patients with LMM in more detail than available in the previous literature and raises several questions that warrant further investigation. Prospective studies that are adequately powered are needed to better evaluate the prognosis of LMM and determine whether it is significantly different from Stage I DMM and/or from WDPM. Although most IMP LMM patients experienced only localized recurrences, some progressed to DMM and a few lesions metastasized underscoring the need for more meticulous follow up of these lesions to investigate how often they evolve into DMM and whether molecular studies, proteomics or other methodologies can help predict which LMM are likely to do so. There is also a need to investigate the role of asbestos in the causation of LMM, perhaps with multiinstitutions case-control series and with tissue burden analysis of lung tissues. Finally, pathologists, radiologists, thoracic surgeons, and oncologists need to become aware that not all mesotheliomas are DMM, so that aggressive surgery, neoadjuvant, and/or adjuvant therapeutic modalities are considered for the initial treatment of LMM patients.

\section{Compliance with ethical standards}

Conflict of interest AMM,VR, LRC and MBB have provided expert testimony in asbestos litigation. The other authors declare that they have no conflict of interest.

Publisher's note: Springer Nature remains neutral with regard to jurisdictional claims in published maps and institutional affiliations.

\section{References}

1. Marchevsky AM, Husain A, Galateau-Sallé F. Practical pathology of serous membranes. Cambridge, U.K.: Cambridge University Press; 2019.

2. Du Bray ERFB. Primary mesothelioma of the pleura: a clinical and pathologic contribution to the pleural malignancy, with report of a case. Arch Intern Med. 1920;26:715-37.
3. Klemperer P, Rabin CB. Primary neoplasms of the pleura. A report of five cases. Arch Pathol. 1931;33:385-412.

4. Berzenji L, Van Schil P. Multimodality treatment of malignant pleural mesothelioma. F1000Res. 2018;7. https://www.ncbi.nlm.nih. gov/pmc/articles/PMC6198256/pdf/f1000research-7-17243.pdf.

5. Bibby AC, Maskell NA. Current treatments and trials in malignant pleural mesothelioma. Clin Respir J. 2018;12:2161-9.

6. Case BW. Pathology analysis for mesothelioma study in the United Kingdom: current practice and historical development. J Toxicol Environ Health B Crit Rev. 2016;19:201-12.

7. Ascoli V, Minelli G, Cozzi I, Romeo E, Carnovale Scalzo C, Ancona L, et al. Pathology reporting of malignant pleural mesothelioma first diagnosis: a population-based approach. Pathol Res Pract. 2016;212:886-92.

8. Petrelli F, Ardito R, Conti B, Coinu A, Cabiddu M, Ghilardi M, et al. A systematic review and meta-analysis of second-line therapies for treatment of mesothelioma. Respir Med. 2018;141:72-80.

9. Rosen LE, Karrison T, Ananthanarayanan V, Gallan AJ, Adusumilli PS, Alchami FS, et al. Nuclear grade and necrosis predict prognosis in malignant epithelioid pleural mesothelioma: a multiinstitutional study. Mod Pathol. 2018;31:598-606.

10. Raskin J, Surmont V, Cornelissen R, Baas P, van Schil PEY, van Meerbeeck JP. A randomized phase II study of pleurectomy/decortication preceded or followed by (neo-)adjuvant chemotherapy in patients with early stage malignant pleural mesothelioma (EORTC 1205). Transl Lung Cancer Res. 2018; 7:593-8.

11. Rusch VW, Chansky K, Kindler HL, Nowak AK, Pass HI, Rice DC, et al. Prognostic factors committee ab, participating i. The IASLC mesothelioma staging project: proposals for the $M$ descriptors and for revision of the TNM stage groupings in the forthcoming (eighth) edition of the TNM classification for mesothelioma. J Thorac Oncol. 2016;11:2112-9.

12. Deraco M, Nizri E, Glehen O, Baratti D, Tuech JJ, Bereder JM, et al. Well differentiated papillary peritoneal mesothelioma treated by cytoreduction and hyperthermic intraperitoneal chemotherapy-the experience of the PSOGI registry. Eur J Surg Oncol. 2019;45:371-5.

13. Vogin G, Hettal L, Vignaud JM, Dartigues P, Goere D, Ferron G, et al. Well-differentiated papillary mesothelioma of the peritoneum: a retrospective study from the RENAPE observational registry. Ann Surg Oncol. 2019;26:852-60.

14. Sun M, Zhao L, Weng Lao I, Yu L, Wang J. Well-differentiated papillary mesothelioma: A 17-year single institution experience with a series of 75 cases. Ann Diagn Pathol. 2019;38:43-50.

15. Stevers M, Rabban JT, Garg K, Van Ziffle J, Onodera C, Grenert $\mathrm{JP}$, et al. Well-differentiated papillary mesothelioma of the peritoneum is genetically defined by mutually exclusive mutations in TRAF7 and CDC42. Mod Pathol. 2019;32:88-99.

16. Mann S, Khawar S, Moran C, Kalhor N. Revisiting localized malignant mesothelioma. Ann Diagn Pathol. 2019;39:74-77.

17. Hino T, Kamitani T, Sagiyama K, Yamasaki Y, Okamoto I, Tagawa $\mathrm{T}$, et al. Localized malignant pleural mesothelioma mimicking an anterior mediastinal tumor. Eur J Radiol Open. 2019;6:72-77.

18. Guo X, Watanabe J, Takahashi K, Hayashi T, Kurose N, Sasaguri $\mathrm{Y}$, et al. Localized malignant pleural mesothelioma arising in the interlobar fissure: a unique surgical case masquerading clinicopathologically as primary lung adenocarcinoma. SAGE Open Med Case Rep. 2019;7:2050313X18824802.

19. Song G, Bi W, Zhang X, Huang W, Zhou K, Ren W. Localized primary malignant pericardial mesothelioma. J Clin Ultrasound. 2019;47:178-81.

20. Kim KC, Vo HP. Localized malignant pleural sarcomatoid mesothelioma misdiagnosed as benign localized fibrous tumor. J Thorac Dis. 2016;8:E379-384. 
21. Zardawi SJ, Li BT, Zauderer MG, Wang JW, Atmore BB, Barnes TA, et al. Localized malignant pleural mesothelioma with renal metastasis. Oxf Med Case Rep. 2015;2015:170-2.

22. Kohno M, Maruyama R, Kitagawa D, Sugimachi K, Kinjo M, Higashi H. Localized biphasic type malignant mesothelioma arising in the peritoneum: report of a case. Thorac Cancer. 2014;5:74-77.

23. Kim Y, Lee E, Jung W, Kim HK, Jung SH, Hong KD, et al. Localized malignant peritoneal mesothelioma arising in the mesentery of the ascending colon. Am Surg. 2012;78:E255-257.

24. Price B, Ware A. Time trend of mesothelioma incidence in the United States and projection of future cases: an update based on SEER data for 1973 through 2005. Crit Rev Toxicol. 2009; 39:576-88.

25. Alhatem A, Marcus J, Heller DS. Multicystic mesothelioma of the omentum presenting as an incidental finding. Int J Surg Pathol. 2019;27:174-5.

26. Nizri E, Baratti D, Guaglio M, Sinukumar S, Cabras A, Kusamura S, et al. Multicystic mesothelioma: Operative and long-term outcomes with cytoreductive surgery and hyperthermic intra peritoneal chemotherapy. Eur J Surg Oncol. 2018;44:1100-4.

27. Desrumaux I, Baekelandt M, Verbeke W, Gryspeerdt S, Van Holsbeeck B, Lefere P. Localized benign fibrous mesothelioma mimicking a malignant tumor of the pleura. JBR-BTR. 1998; $81: 131-3$

28. Dervan PA, Tobin B, O'Connor M. Solitary (localized) fibrous mesothelioma: evidence against mesothelial cell origin. Histopathology. 1986;10:867-75.

29. Ershadi R, Rahim M, Abbasi M, Erfanian R. Giant solitary fibrous tumor of the pleura. J Surg Case Rep. 2018;2018:rjy270.

30. Yamamoto Y, Kanzaki R, Inoue M, Okumura M. Primary solitary fibrous tumor of the forearm with frequent late-onset recurrence in the pleura. Ann Thorac Surg. 2017;104:e173-e175.

31. Kanthan R, Torkian B. Recurrent solitary fibrous tumor of the pleura with malignant transformation. Arch Pathol Lab Med. 2004;128:460-2.

32. Altin R, Erol Y, Ozdemir H, Kart L, Ozen O, Mahmutyazyeyoglu K. Localized benign pleural mesothelioma: a case report. Monaldi Arch Chest Dis. 2003;59:166-8.

33. Henderson DS, Shilkin KB, Whitaker D. The pathology of mesothelioma, including immunohistology and ultrastructure. In: Henderson DS, KB, Langlois SL, Whitaker D, editors. Malignant Mesothelioma. New York: Hemisphere; 1992. p. 69-139.

34. Crotty TB, Myers JL, Katzenstein AL, Tazelaar HD, Swensen SJ, Churg A. Localized malignant mesothelioma. A clinicopathologic and flow cytometric study. Am J Surg Pathol. 1994;18:357-63.

35. Okike N, Bernatz PE, Woolner LB. Localized mesothelioma of the pleura: benign and malignant variants. $\mathrm{J}$ Thorac Cardiovasc Surg. 1978;75:363-72.

36. Obers VJ, Leiman G, Girdwood RW, Spiro FI. Primary malignant pleural tumors (mesotheliomas) presenting as localized masses. Fine needle aspiration cytologic findings, clinical and radiologic features and review of the literature. Acta Cytol. 1988;32:567-75.

37. Allen TC, Cagle PT, Churg AM, Colby TV, Gibbs AR, Hammar SP, et al. Localized malignant mesothelioma. Am J Surg Pathol. 2005;29:866-73.

38. Akamoto S, Ono Y, Ota K, Suzaki N, Sasaki A, Matsuo Y, et al. Localized malignant mesothelioma in the middle mediastinum: report of a case. Surg Today. 2008;38:635-8.

39. Andrews W, Paul S, Narula N, Altorki NK. Localized mesothelioma tumour arising synchronously with a primary contralateral lung cancer. Interact Cardiovasc Thorac Surg. 2013;17:1061-2.

40. Dalton WT, Zolliker AS, McCaughey WT, Jacques J, Kannerstein M. Localized primary tumors of the pleura: an analysis of 40 cases. Cancer. 1979;44:1465-75.
41. Dimarakis I, Rehman S, Machaal A, Shah R. PET-CT in the diagnosis of localized malignant pleural mesothelioma. Clin Imaging. 2011;35:476-7.

42. Erdogan E, Demirkazik FB, Gulsun M, Ariyurek M, Emri S, Sak SD. Incidental localized (solitary) mediastinal malignant mesothelioma. Br J Radiol. 2005;78:858-61.

43. Erkilic S, Sari I, Tuncozgur B. Localized pleural malignant mesothelioma. Pathol Int. 2001;51:812-5.

44. Espinal-Witter R, Servais EL, Klimstra DS, Lieberman MD, Yantiss RK. Localized intrapancreatic malignant mesothelioma: a rare entity that may be confused with other pancreatic neoplasms. Virchows Arch. 2010;456:455-61.

45. Gelvez-Zapata SM, Gaffney D, Scarci M, Coonar AS. What is the survival after surgery for localized malignant pleural mesothelioma? Interact Cardiovasc Thorac Surg. 2013;16:533-7.

46. Giansanti M, Bellezza G, Guerriero A, Pireddu A, Sidoni A. Localized intrasplenic mesothelioma: a case report. Int J Surg Pathol. 2014;22:451-5.

47. Gomez-Roman JJ, Mons-Lera R, Olmedo IS, Val-Bernal JF. Flow cytometric analysis of a localized malignant mesothelioma. Ann Thorac Surg. 2002;73:1292-4.

48. Gomez-Roman JJM-L R, Val-Bernal JF. Flow cytometric analysis of a localized malignant mesothelioma. Ann Thorac Surg. 2002; 73:1292-4.

49. Gotfried MH, Quan SF, Sobonya RE. Diffuse epithelial pleural mesothelioma presenting as a solitary lung mass. Chest. 1983; 84:99-101.

50. Hayashi H, Notohara K, Yoshioka H, Matsuoka T, Ikeda H, Kagawa K, et al. Localized malignant pleural mesothelioma showing a thoracic mass and metastasizing to the stomach. Intern Med. 2010;49:671-5.

51. Hirano H, Takeda S, Sawabata Y, Okumura Y, Maeda H, Hanibuchi $\mathrm{M}$, et al. Localized pleural malignant mesothelioma. Pathol Int. 2003;53:616-21.

52. Liu H, Cheng YJ, Chen HP, Hwang JC, Chang PC. Multiple bowel intussusceptions from metastatic localized malignant pleural mesothelioma: a case report. World J Gastroenterol. 2010;16:3984-6.

53. Imura J, Ichikawa K, Takeda J, Iwasaki Y, Tomita S, Kubota K, et al. Localized malignant mesothelioma of the epithelial type occurring as a primary hepatic neoplasm: a case report with review of the literature. APMIS. 2002;110:789-94.

54. Kato K, Gemba K, Fujimoto N, Aoe K, Takeshima Y, Inai K, et al. Fatal pleural mesothelioma in Japan (2003-8): evaluation of computed tomography findings. Jpn J Radio. 2016;34:432-8.

55. Khalil MW, Campbell AP, Cowen ME. Epithelioid malignant mesothelioma presenting with features of esophageal tumor. Asian Cardiovasc Thorac Ann. 2011;19:260-1.

56. Khan AM, Tlemcani K, Shanmugam N, Y D, Keller S, Berman AR. A localized pleural based mass with intense uptake on positron emission tomography scan. Chest. 2007;131:294-9.

57. Ko HM, Kamil ZS, Geddie WR. Microcystic variant malignant mesothelioma presenting as a localized paraspinal mass. Cytojournal. 2014;11:16.

58. Kuroda K, Ishizawa S, Kudo T, Uotani H, Hosokawa A, Tanaka $\mathrm{T}$, et al. Localized malignant mesenteric mesothelioma causing small bowel obstruction. Pathol Int. 2008;58:239-43.

59. Liu H, Cheng YJ, Chen HP, Hwang JC, Chang PC. Multiple bowel intussusceptions from metastatic localized malignant pleural mesothelioma: a case report. World J Gastroenterol. 2010;16:3984-6.

60. Maeda R, Isowa N, Onuma H, Miura H, Tokuyasu H, Kawasaki Y. Minute localized malignant pleural mesothelioma coexisting with multiple adenocarcinomas. Gen Thorac Cardiovasc Surg. 2010;58:91-94. 
61. Nakano T, Hamanaka R, Oiwa K, Nakazato K, Masuda R, Iwazaki M. Localized malignant pleural mesothelioma. Gen Thorac Cardiovasc Surg. 2012;60:468-74.

62. Nakano T, Maeda J, Iwahashi N, Tamura S, Hada T, Higashino K. Gallium-67 scanning in patients with malignant pleural mesothelioma. Jpn J Med. 1990;29:255-60.

63. Ojeda HF, Mech K Jr., Hicken WJ. Localized malignant mesothelioma: a case report. Am Surg. 1998;64:881-5.

64. Okamura H, Kamei T, Mitsuno A, Hongo H, Sakuma N, Ishihara T. Localized malignant mesothelioma of the pleura. Pathol Int. 2001;51:654-60.

65. Ouazzani A, Rondelet B, Sokolow Y, Ruiz Patino M, Remmelink M, Cappello M. Localized malignant lymphohistiocytoid pleural mesothelioma. Acta Chir Belg. 2011;111:38-43.

66. Papalambros A, Sigala F, Vouza EG, Hepp W, Antonakis P. Sister Mary Joseph's nodule as primary localized malignant mesothelioma. Report of a case. Zent Chir. 2011;136:172-4.

67. Robinson LA, Reilly RB. Localized pleural mesothelioma. Clin Spectr Chest. 1994;106:1611-5.

68. Sasaki M, Araki I, Yasui T, Kinoshita M, Itatsu K, Nojima T, et al. Primary localized malignant biphasic mesothelioma of the liver in a patient with asbestosis. World J Gastroenterol. 2009;15:615-21.

69. Takahashi H, Harada M, Maehara S, Kato H. Localized malignant mesothelioma of the pleura. Ann Thorac Cardiovasc Surg. 2007;13:262-6.

70. Tanzi S, Tiseo M, Internullo E, Cacciani G, Capra R, Carbognani $\mathrm{P}$, et al. Localized malignant pleural mesothelioma: report of two cases. J Thorac Oncol. 2009;4:1038-40.

71. Turna A, Pekcolaklar A, Fener N, Gurses A. Localized malignant pleural mesothelioma treated by a curative intent lobectomy: a case report. Ann Thorac Cardiovasc Surg. 2007;13:349-51.

72. Umezu H, Kuwata K, Ebe Y, Yamamoto T, Naito M, Yamato Y, et al. Microcystic variant of localized malignant mesothelioma accompanying an adenomatoid tumor-like lesion. Pathol Int. 2002;52:416-22.

73. Yao W, Yang H, Huang G, Yan Y, Wang H, Sun D. Massive localized malignant pleural mesothelioma (LMPM): manifestations on computed tomography in 6 cases. Int J Clin Exp Med. 2015;8:18367-74.

74. You Q, Zhao J, Shi G, Deng J, Teng X. Epithelioid malignant mesothelioma presenting with features of gastric tumor in a child. Int J Clin Exp Pathol. 2014;7:2636-40.

75. Galateau Salle F, Le Stang N, Nicholson AG, Pissaloux D, Churg A, Klebe S, et al. New insights on diagnostic reproducibility of biphasic mesotheliomas: a multi-institutional evaluation by the International mesothelioma panel from the MESOPATH reference center. J Thorac Oncol. 2018;13:1189-203.

76. Marchevsky AM, LeStang N, Hiroshima K, Pelosi G, Attanoos R, Churg A, et al. The differential diagnosis between pleural sarcomatoid mesothelioma and spindle cell/pleomorphic (sarcomatoid) carcinomas of the lung: evidence-based guidelines from the International mesothelioma panel and the MESOPATH National reference center. Hum Pathol. 2017;67:160-8.

77. Marchevsky AM, Wick MR. Evidence-based pathology: systematic literature reviews as the basis for guidelines and best practices. Arch Pathol Lab Med. 2015;139:394-9.

78. Marchevsky AM, Wick MR. Evidence levels for publications in pathology and laboratory medicine. Am J Clin Pathol. 2010; 133:366-7.

79. Marchevsky AM, Wick MR. Evidence-based medicine, medical decision analysis, and pathology. Hum Pathol. 2004;35:1179-88.

80. Asioli S, Dal Piaz G, Damiani S. Localised pleural malignant mesothelioma. Report of two cases simulating pulmonary carcinoma and review of the literature. Virchows Arch. 2004; 445:206-9.

81. Kim DS, Lee SG, Jun SY, Kim KW, Ha TY, Kim KK. Primary malignant mesothelioma developed in liver. Hepatogastroenterology. 2008;55:1081-4.

82. Leonardou P, Semelka RC, Kanematsu M, Braga L, Woosley JT. Primary malignant mesothelioma of the liver: MR imaging findings. Magn Reson Imaging. 2003;21:1091-3.

83. Gutgemann I, Standop J, Fischer HP. Primary intrahepatic malignant mesothelioma of epithelioid type. Virchows Arch. 2006;448:655-8.

84. Nakas A, Martin-Ucar AE, Edwards JG, Waller DA. Localised malignant pleural mesothelioma: a separate clinical entity requiring aggressive local surgery. Eur J Cardiothorac Surg. 2008;33:303-6.

85. Buchholz BM, Gutgemann I, Fischer HP, Gorschluter M, Turler A, Kalff JC, et al. Lymph node dissection in primary intrahepatic malignant mesothelioma: case report and implications for diagnosis and therapy. Langenbecks Arch Surg. 2009;394:1123-30.

86. Zhang S, Song P, Zhang B. Giant malignant mesothelioma in the upper mediastinum: a case report. Oncol Lett. 2013;6:181-4.

87. Inagaki N, Kibata K, Tamaki T, Shimizu T, Nomura S. Primary intrahepatic malignant mesothelioma with multiple lymphadenopathies due to non-tuberculous mycobacteria: a case report and review of the literature. Oncol Lett. 2013;6:676-80.

88. Fujita K, Hata M, Sezai A, Minami K. Three-year survival after surgery for primary malignant pericardial mesothelioma: report of a case. Surg Today. 2014;44:948-51.

89. Perysinakis I, Nixon AM, Spyridakis I, Kakiopoulos G, Zorzos C, Margaris I. Primary intrahepatic malignant epithelioid mesothelioma. Int J Surg Case Rep. 2014;5:1098-101.

90. Haji Ali R, Khalife M, El Nounou G, Zuhri Yafi R, Nassar H, Aidibe $\mathrm{Z}$, et al. Giant primary malignant mesothelioma of the liver: a case report. Int J Surg Case Rep. 2017;30:58-61.

91. Ismael H, Cox S. Primary intrahepatic mesotheliomas: a case presentation and literature review. Int $\mathbf{J}$ Surg Case Rep. 2018;47:1-6.

92. Baqui AA, Boire NA, Baqui TT, Etwaru DJ. Malignant mesothelioma of the tunica vaginalis testis-a malignancy associated with asbestos exposure and trauma: a case report and literature review. J Investig Med High Impact Case Rep. 2019;7:2324709619827335.

93. Harris MC, Logan C, Chetwood A, Cohen P, Titus J, Tan TH, et al. Malignant mesothelioma of the tunica vaginalis: a atypical presentation of a rare scrotal tumour. ANZ J Surg. 2019.

94. Rebecca C, Connor MJ, Sun L, Johnston T, Gooch R, McLoughlin J. Mesothelioma subtypes of the tunica vaginalis: a rare case report and review of histological criteria. J Surg Case Rep. 2019;2019:rjz040.

95. Son NV, Chambers JK, Shiga T, Kishimoto TE, Kikuhara S, Saeki K, et al. Sarcomatoid mesothelioma of tunica vaginalis testis in the right scrotum of a dog. J Vet Med Sci. 2018;80:1125-8.

96. Trenti E, Palermo SM, D'Elia C, Comploj E, Pycha A, Carella R, et al. Malignant mesothelioma of tunica vaginalis testis: report of a very rare case with review of the literature. Arch Ital Urol Androl. 2018;90:212-4.

97. Pass H, Giroux D, Kennedy C, Ruffini E, Cangir AK, Rice D, et al. Prognostic factors committee AB, participating I the IASLC mesothelioma staging project: improving staging of a rare disease through International participation. J Thorac Oncol. 2016;11:2082-8.

98. Malpica A, SantAmbrogio S, Deavers MT, Silva EG. Welldifferentiated papillary mesothelioma of the female peritoneum: a clinicopathologic study of 26 patients. Am J Surg Pathol. 2012;36:117-1. 